\title{
Existem diferenças de gênero na dor no pescoço e nos distúrbios musculloesqueléticos da coluna cervical associados a migrânea?
}

\author{
Nathan da Silva Xavier ${ }^{1}$ (D) Mariana Tedeschi Benatto' ${ }^{1}$ (D) Lidiane Lima Florencio $^{2}$ (D), \\ César Fernández-de-las-Peñas ${ }^{2}$ (D) Fabiola Dach $^{1}{ }^{1 D}$, Débora Bevilaqua-Grossi ${ }^{1}$ (D)
}

\begin{abstract}
'Faculdade de Medicina de Ribeirão Preto, Universidade de São Paulo, Brasil.
¿Universidade Rey Juan Carlos, Alcorcón, Madri, Espanha.
\end{abstract}

\author{
Introdução \\ Dor cervical e disfunções musculoesqueléticas parecem estar associadas à migrânea. No entanto, os estudos que \\ investigaram essas associações foram realizados majoritariamente em mulheres.
}

\section{Objetivo}

Verificar se migranosos apresentam diferenças entre os gêneros em relação à dor e incapacidade no pescoço, no desempenho dos músculos flexores profundos da cervical e na mobilidade passiva da coluna cervical superior.

\begin{abstract}
Métodos
A amostra foi composta por 30 homens e 30 mulheres, com idade entre 18 e 55 anos, com diagnóstico de migrânea de acordo com a Classificação Internacional de Cefaleia. Foram excluídos indivíduos com diagnóstico de outras cefaleias ou doenças sistêmicas. Os participantes foram questionados sobre a presença de dor no pescoço e aqueles que relataram sintomas responderam ao questionário Neck Disability Index (NDI). Foi realizado o Flexion Rotation Test (FRT) para avaliar a mobilidade da coluna cervical superior e o Craniocervical Flexion Test (CCFT), para avaliar o desempenho dos músculos flexores profundos da coluna cervical. O estudo foi aprovado pelo Comitê de Ética em Pesquisa (HCRP n $\left.{ }^{\circ} 6644 / 2018\right)$.
\end{abstract}

\section{Resultados}

A comparação entre os grupos foi realizada usando os testes $\dagger$ de Student e qui-quadrado. A razão de prevalência também foi calculada e um nível de significância de $\mathrm{p}<0,05$ foi adotado. As mulheres apresentaram maior relato de dor cervical $(p=0,04)$ e uma associação ao risco 1,69 maior em relatar esse sintoma em relação aos homens $(p=0,02)$. No entanto, os grupos não apresentaram diferenças significativas na incapacidade cervical pelo NDI $(p=0.25)$, na mobilidade pelo FRT $(p=0,92)$ e no desempenho pelo CCFT $(p=0,52)$.

\section{Conclusão}

Mulheres com migrânea apresentam maior prevalência de relato de dor cervical, no entanto os testes clínicos da coluna cervical não diferem entre os gêneros. Portanto, os achados desse estudo apontam para a necessidade de avaliação da coluna cervical para um manejo terapêutico adequado em ambos os sexos.

Palavras-chave: Migrânea, Gênero, Dor no pescoço 